\title{
De Molière à Marivaux, édition électronique sous la direction de Barbara Sommovigo
}

\section{Monica Pavesio}

\section{(2) OpenEdition}

12 Journals

\section{Edizione digitale}

URL: http://journals.openedition.org/studifrancesi/9527

DOI: $10.4000 /$ studifrancesi.9527

ISSN: 2421-5856

\section{Editore}

Rosenberg \& Sellier

\section{Edizione cartacea}

Data di pubblicazione: 1 décembre 2007

Paginazione: 654

ISSN: 0039-2944

\section{Notizia bibliografica digitale}

Monica Pavesio, «De Molière à Marivaux, édition électronique sous la direction de Barbara

Sommovigo», Studi Francesi [Online], 153 (LI | III) | 2007, online dal 30 novembre 2015, consultato il 09 janvier 2021. URL: http://journals.openedition.org/studifrancesi/9527 ; DOI: https://doi.org/10.4000/ studifrancesi.9527

Questo documento è stato generato automaticamente il 9 janvier 2021.

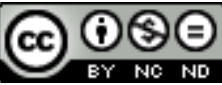

Studi Francesi è distribuita con Licenza Creative Commons Attribuzione - Non commerciale - Non opere derivate 4.0 Internazionale. 


\title{
De Molière à Marivaux, édition électronique sous la direction de Barbara Sommovigo
}

\author{
Monica Pavesio
}

\section{NOTIZIA}

De Molière à Marivaux, édition électronique sous la direction de Barbara sommovigo, Pisa, Edizioni ETS, 2006.

1 Il CD-ROM contenente le principali commedie francesi del fecondo periodo che va dalla morte di Molière a Marivaux, ossia l'intera produzione comica dei drammaturghi più rappresentativi della seconda metà del secolo - Molière, Hauteroche, Chappuzeau, Chevalier, Poisson, Champmeslé, Baron, Regnard, Dufresny, Dancourt, Nivelle de La Chaussée, Marivaux -, messo a punto da Barbara Sommovigo e da alcuni suoi collaboratori (Cristiana BERTI, Luciano CARCERERI, Pino NONNE e Elisabetta SIBILIO, curatrice delle commedie di Molière), è uno strumento di grande utilità per gli studiosi del teatro francese secentesco.

2 Per installare il CD-ROM è necessario possedere un sistema operativo Microsoft Windows 95, 98 o XP, dotato di lettore CD o DVD.

3 Accompagnano l'edizione elettronica delle commedie, un libro di presentazione e un manuale per l'istallazione e l'utilizzo del DBT, il Data Base Testuale messo a punto da Eugenio Picchi dell'Istituto di Linguistica Comparata del CNR di Pisa. Grazie al data base è possibile interrogare i singoli testi o un corpus di testi selezionati, per ritrovare le concordanze, definire la frequenza e la localizzazione delle parole chiave, stabilire legami fra le opere dello stesso autore o di autori diversi, ma pubblicate nello stesso anno. 
4 Le edizioni critiche, attuate con metodi conservativi e utilizzando la collazione fra l'editio princeps e le edizioni successive, sono accurate e accompagnate da un glossario elettronico costituito a partire dai principali dizionari dell'epoca.

5 Si auspica che l'utile progetto diretto da Barbara Sommovigo venga portato avanti e ampliato, magari con le commedie dei drammaturghi contemporanei di Molière, o con le tragedie e le tragicommedie del periodo. 